\section{Making sport and sports medicine history-Lillehammer 1994, 2019 and 2021}

\author{
Hilde Moseby Berge ${ }^{\odot}$
}

Welcome to this scintillating Norwegian issue of the BJSM. The Scandinavian knee ligament registries (See page 1259) were established 15 years ago, and they now inform us with data from $>70000$ patients. Did you know that you can lower the risk of revision anterior cruciate ligament (ACL) reconstruction for hamstring versus patella tendon autograft by $14 \%$ for every $0.5 \mathrm{~mm}$ increase in hamstring graft diameter? ${ }^{1}$

In a cohort of professional male Norwegian football players followed up after 8 years (See page 1279), we found that 6 of the 595 players with negative preparticipation cardiac screening suffered a severe cardiovascular event; three of these six events were sudden cardiac arrests (SCA). Rather than introducing more preparticipation cardiac screening in Norway, we will focus on recognising athletes with early symptoms of cardiac disease. We will examine them thoroughly, and be prepared to treat SCA by having staff well trained and AEDs widely available. It is critical to recognise SCA early as proven by another Norwegian study (See page 1293) where authors analysed 35 sports-related SCAs that were captured on video. Agonal respiration, prone landing, seizure-like activity and abnormal eye gaze occurred in $66 \%$ of the events. Early cardiopulmonary resuscitation by bystanders is critical.

Sticking with the theme of early detection of disease, we should 'adopt more thoughtful management approaches and referral practices that empower patients to engage in shared decision making based on the best available evidence'. This advice about preventing overdiagnosis and harms of too much medicine (See page 1314) is in line with the conclusion of two other papers, discussing the value of MRI of knees. In the first study (See page 1285), a multicentre randomised controlled trial, Swart and colleagues found no evidence that adding MRI to usual care in general practice for patients aged $18-45$ years with traumatic knee complaints affected knee-related

Correspondence to Dr Hilde Moseby Berge, Oslo Sports Trauma Research Center, Department of Sports Medicine, Norwegian School of Sport Sciences, Oslo 0840, Norway; HildeMoseby.Berge@olympiatoppen.no daily function a year later. In the second study (See page 1268), Culvenor et al's systematic review and meta-analysis found knee osteoarthritis features on MRI in near half the knees in otherwise healthy, asymptomatic, uninjured adults aged $\geq 40$ years. Both studies draw attention to the importance of providing correct information to patients in needor not-of healthcare. Despite no difference in physical outcome or quality of life, patients in the first study were more satisfied with their treatment if they were randomised to (unnecessary) MRI. This paper is not the only one to emphasise the effect of patients' perception of healthcare, on level of treatment and perceived outcome. In O'Keeffe et al's editorial (See page 1261), they give several examples of how public misconceptions of backpain causes overtreatment. But fortunately, they provide suggestions for how to inform the public to 'don't take the back pain lying down', based on a successful mass media campaign aired in the late 1990s. A similar campaign today, will include social media platforms, with 'sticky' messages targeted to different people. Martin Sinclair, represented in a patient voice paper (See page 1321), was born with cerebral palsy and got back to football after having total hip replacement (twice). He highlights that 'Mindset is key!' and encourages to help patients develop a 'can do' rather than a 'can't do' mindset.

Infographics is a popular way to promote key messages and that brings us to the last topic in this issue. Take a note of the highly increased risk of overheating, as well as potential performance decrements in athletes with tetraplegia in the infographic of thermoregulation in patients with spinal cord injury by Griggs et al (See page 1305). Facing the hot and humid environments during the Olympic and Paralympic Games in Tokyo 2020, we all need to know the impact of this temperature, and how to counter the harms. We can probably learn from Snipe's carefully executed studies of prevention and management strategies of exertional heat stress-induced gastrointestinal perturbations in amateur athletes, presented as the

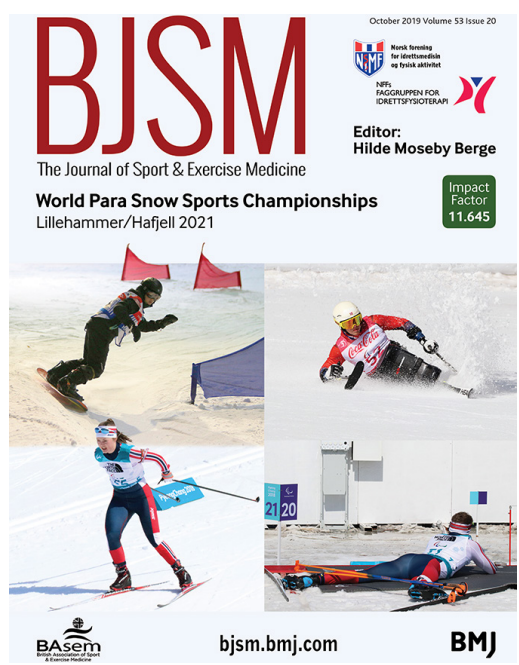

PhD Academy Award (See page 1312). In short, combine water at a temperature of $22^{\circ} \mathrm{C}$ with regular carbohydrate consumption to support gastrointestinal health and reduce upper gastrointestinal symptoms during endurance running in the heat.

\section{SKIING IN THE 1994 OLYMPIC CITY- LILLEHAMMER, NORWAY}

Over the last year, I have had the pleasure to get to know sport and exercise medicine professor Katherine Dec. She was the President of our US counterpart medical society the American Medical Society for Sports Medicine (AMSSM, @TheAMSSM) in 2017-2018 and you read about her in this issue's Inside track. She was the catalyst for the establishment of a formal exchange between sport and exercise medicine physicians in the US (AMSSM) and Norway (The Norwegian Association of Sport and Exercise Medicine, NIMF). As a person who puts enough effort to achieve what she wants, it would not surprise me if she returns to Norway having practised cross-country skiing! Skiing skills will be beneficial if you want to be part of the history in February 2021. Norway's Olympic city, Lillehammer, will host the first joint World Para Snow Sports Championships in Para alpine skiing, Para Nordic skiing and Para snowboard. But first, Lillehammer will host the Norwegian Sports Medicine Conference from 22 to 24 November 2019. Our overseas visitors rave about the meeting and most of the programme is in English. Your over 500 Norwegian counterparts all speak English and will make you welcome! (https://www.imhk2019.com/).

Have an adventure!

Contributors Hilde Moseby Berge is the sole author of this publication.

Competing interests None declared.

Patient consent for publication Not required. 
Provenance and peer review Not commissioned; internally peer reviewed.

(c) Author(s) (or their employer(s)) 2019. No commercial re-use. See rights and permissions. Published by BMJ.

(A) Check for updates
To cite Berge HM. Br J Sports Med 2019;53:1257-1258.

Accepted 13 August 2019

Br J Sports Med 2019;53:1257-1258.

doi:10.1136/bjsports-2019-101352

\section{REFERENCE}

1 Snaebjörnsson T, Hamrin Senorski E, Ayeni OR, et al. Graft diameter as a predictor for revision anterior cruciate ligament reconstruction and KOOS and EQ-5D values: a cohort study from the Swedish national knee ligament register based on 2240 patients. Am I Sports Med 2017;45:2092-7. 